\title{
Фиктивные предприятия: найти и обезвредить
}

\author{
Н.С. МИХАЙЛОВА, кандидат экономических наук, Уральский юридический \\ институт МВД России, Екатеринбург. E-mail: Lady.mix2014@mail.ru \\ C.Е. МАРКОВ, Управление экономической безопасности и противодействия \\ коррупции УМВД России по Сахалинской области, Южно-Сахалинск. \\ E-mail: Markov94jobs@gmail.com
}

В статье поднимается проблема распространения фиктивных организаций, возникших в процессе развития теневых явлений в экономике, по причине которых страна ежегодно несет огромные убытки и возникают недоимки в бюджете. Перечислены типичные признаки фирм-однодневок, показатели, указывающие на налоговые риски. Также авторами представлен генезис становления фиктивных организаций, проанализированы основные их типы и виды деятельности. Сделан вывод, что объемы и масштабы теневой экономики установить достаточно сложно, таким образом, по оценкам экспертов и информационных систем можно определить (с высокой долей погрешности) лишь примерное количество фиктивных организаций. На основе официальных данных (программа «СПАРК») показана динамика, отражающая тенденции по сокращению числа рассматриваемых фирм. В статье также предложены мероприятия по усилению этой тенденции.

Ключевые слова: теневая экономика, фирма-однодневка, предпринимательство, показатели, противодействие

Теневые процессы в экономике происходят в большинстве стран мира, различия связаны в основном с масштабами данного явления. В России неформальные связи между государственным аппаратом, хозяйствующими субъектами и физическими лицами были распространены еще в период действия плановой системы и не преодолены до сих пор. Теневые процессы приводят к сокращению налоговых поступлений в бюджет, искажению конкурентной среды в пользу отдельных предприятий («покупка» привилегий) [Буров, 2014].

В настоящее время выделяют институциональную и неоинституциональную теории теневизации экономических процессов [Артемьев, Латов, 2015]. Первая раскрывает сложившиеся тенденции и генезис трансформации определенных институтов в факторы влияния [Schneider F., Enste D., 2000], вторая определяет в качестве основной причины развития теневого предпринимательства действия хозяйствующего субъекта, провоцирующие неофициальные или нелегальные операции со стороны третьих лиц [Колесников, 2016]. 
Изучению причин и социально-экономических последствий теневых процессов в экономике посвящено немало научных трудов в России и за рубежом.

\section{Как распознать фиктивное предприятие}

В качестве отличительных черт теневого сектора можно обозначить сокрытие доходов от налогового контроля, противоправный характер действий, несоответствие деятельности законодательной базе и отсутствие системы как внутреннего, так и внешнего учета по причине отсутствия единой методологии на уровне макро- и микрометодов.

Одним из секторов теневой или иррегулируемой экономики являются фиктивные организации, или фирмы-однодневки. Как показывает практика, они обладают высоким адаптационным уровнем, позволяющим оперативно подстраиваться под постоянно меняющиеся условия среды [Dallado, 1991; Глушков, 2008; Латов, 2006]. Под «фирмой-однодневкой» понимается юридическое лицо, не обладающее фактической самостоятельностью, созданное без цели ведения предпринимательской деятельности, как правило, не представляющее налоговую отчетность, и т.д ${ }^{1}$.

В качестве признаков типичной фиктивной организации можно выделить следующие:

- наличие номинального учредителя;

- регистрация предприятия на фиктивный адрес и/или по утраченным документам;

- одно и то же физическое лицо является учредителем в нескольких фирмах;

- отсутствие фактического управления и ведения деятельности хозяйствующего субъекта;

- частая «миграция» юридического лица в форме смены юридического адреса, слияния (поглощения) с другими юридическими лицами;

- кадровый состав не соответствует масштабам организации;

- финансовая (в том числе налоговая) отчетность носит сомнительный характер: показатели деятельности нулевые либо содержат противоречия;

${ }^{1}$ Письмо ФНС РФ от 11.02.2010 N3-7-07/84 «О рассмотрении обращения». [Эл. pecypc]. URL: http://www.consultant.ru/document/cons_doc_LAW_98034/ (дата обращения: 12.03.2018). 
- отсутствие движения средств или преобладание транзитных операций на расчетном счете организации (несколько источников поступления с последующим быстрым списанием);

- финансово-хозяйственная деятельность организации строится на основании заключения агентских или иных посреднических договоров без объективных на то экономических или иных причин;

- отсутствие логической связи в управленческой деятельности (крупные сделки при минимальном объеме собственных средств).

Для выявления фирм-однодневок 30 мая 2007 г. ФНС России был издан Приказ «Об утверждении Концепции системы планирования выездных налоговых проверок»². В приложении № 2 к этому приказу перечислены следующие ситуации, дающие основания сомневаться в добросовестности контрагента, а именно:

- отсутствие личных контактов руководства (уполномоченных должностных лиц) компании-поставщика и компаниипокупателя при обсуждении условий поставок, а также при подписании договоров;

- отсутствие документального подтверждения полномочий руководителя или представителя компании-контрагента, копий документа, удостоверяющего его личность;

- отсутствие информации о фактическом местонахождении контрагента, а также его складских и/или производственных и/ или торговых площадей;

- отсутствие информации о способе получения сведений о контрагенте (нет рекламы в СМИ, нет рекомендаций партнеров или других лиц, нет сайта контрагента и т.п.), в то время как существует доступная информация о других участниках рынка (в том числе производителях) идентичных (аналогичных) товаров (работ, услуг), в том числе предлагающих свои товары (работы, услуги) по более низким ценам;

- отсутствие информации о государственной регистрации контрагента в ЕГРЮЛ (общий доступ, официальный сайт ФНС России www.nalog.ru).

\footnotetext{
${ }^{2}$ Приказ ФНС России от 30.05.2007 N ММ-3-06/333@ (ред. от 10.05.2012) «Об утверждении Концепции системы планирования выездных налоговых проверок» [Эл. pecypc]. URL: http://www.consultant.ru/document/cons_doc_LAW_55729/ (дата обращения: 12.03.2018).
} 


\section{Виды деятельности и этапы развития}

В качестве основных видов незаконной деятельности фиктивных организаций можно выделить следующие:

- получение субсидированной помощи со стороны бюджетов различных уровней (к примеру, открытие организации за счет целевого финансирования, для которого не обязателен год стабильного функционирования);

- уклонение от уплаты налогов (преимущественно на добавленную стоимость и на прибыль;

- затратные схемы и закупки на значительные суммы, фиктивные поставщики и покупатели;

- осуществление операций, связанных с контрабандой (занижение сумм таможенных пошлин, ввоз товаров с нарушением таможенных норм, незаконный экспорт);

- легализация теневого дохода путем «отмывания» прибыли, полученной незаконным путем (приобретение активов предприятия за счет полученных средств; инвестирование; получение кредитов);

- «обналичивание» денежных средств (путем безналичного перевода на расчетный счет организации за фиктивную работу (услугу), как правило, с составлением подтверждающих документов и последующим возвращением этих средств в наличной форме). Вознаграждение фирмы-посредника составляет около 3-8\% (в редких случаях до $10 \%$ );

- посредническое участие в системе государственных закупок (подставной участник тендера, предложивший наименьшую цену реализации контракта с минимальным количеством материальнотрудовых ресурсов и в целом соответствующий выставляемым критериям к организациям-исполнителям).

Можно выделить следующие этапы развития сферы фиктивного предпринимательства в России.

1-й этап: 1990-2000 гг. На фоне высокой предпринимательской активности недостатки законодательной базы в части урегулирования процессов ликвидации и создания предприятий способствовали процветанию теневой экономики. В этот период фирмы-однодневки использовались преимущественно для «обналичивания» денежных средств. Срок их функционирования был менее года (иногда - не более месяца) с последующим 
образованием нового юридического лица, часто без ликвидации предыдущего.

2-й этап: 2000-2010 гг. Ужесточение законодательной базы положило начало борьбе с фиктивными организациями и позволило упорядочить предпринимательскую сферу, сократить неофициальные денежные потоки. Закон «О государственной регистрации юридических лиц и индивидуальных предпринимателей» от 08.08.2001 № 129-Ф3 способствовал выявлению учредителей с недостоверными данными о своей деятельности, с последующим включением в список предприятий с признаками фиктивности. В 2002 г. все организации независимо от организационно-правовой формы должны были получить регистрационный номер (ОГРН). К 2010 г. созданная система ведения учета предприятий позволила идентифицировать их прочим хозяйствующим субъектам в качестве законно действующего контрагента, а государству - как налогоплательщика, тем самым систематизировать и усилить контроль над юридическими лицами.

3-й этап: с 2011 г. по настоящее время. Количество организаций, занимающихся фиктивной предпринимательской деятельностью, заметно сократилось, что зафиксировано созданной в 2010 г. системой «Информационный ресурс “СПАРК”», позволяющей контролировать число субъектов предпринимательства, зарегистрированных в государственных органах, и выявлять неблагонадежные компании (рисунок).

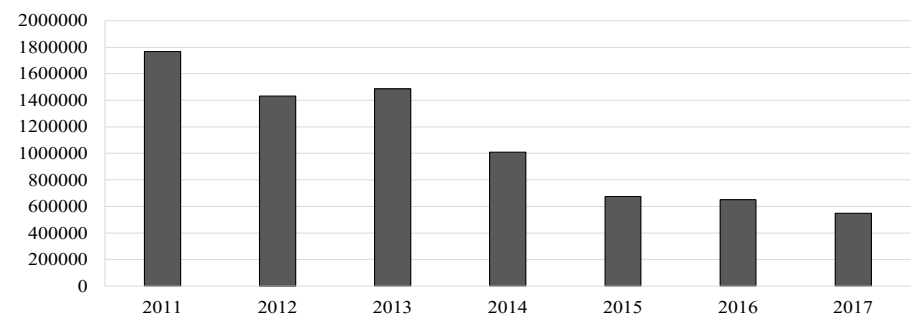

Источник: URL: http://www.spark-interfax.ru/ru/articles (дата обращения: 25.04.2018).

Количество фирм-однодневок за 2011-2017 гг.

Анализируя информацию, представленную на рисунке, необходимо отметить, что в большинстве случаев налоговые органы исключают организации из Единого государственного реестра 
юридических лиц (ЕГРЮЛ) из-за непредоставления итоговой отчетности на протяжении длительного периода, а также отсутствия приходных и расходных операций по банковским счетам (без учета хозяйствующих субъектов, которые произвели реорганизацию, слияния и т.д.).

К сожалению, реальные масштабы теневой деятельности довольно сложно установить, и представленное на рисунке сокращение числа рассматриваемых фиктивных предприятий примерно в 2,5 раза не может быть ключевым показателем действенности мер борьбы, так как, скорее всего, большинство данных организаций лишь сменили профиль деятельности.

В 2011 г. для контроля легализации теневого дохода, полученного нечестным путем как юридическими, так и физическими лицами была создана организация «Росфинмониторинг». Ужесточается контроль со стороны налоговой службы, прокуратуры и правоохранительных органов. Но развитие теневой предпринимательской сферы продолжается, при этом использование фиктивных организаций для уклонения от уплаты налогов и контрабанды сократилось, а для «обналичивания» денежных средств - выросло в разы.

Для выявления фиктивных организаций Федеральной налоговой службой в 2013 г. введена в эксплуатацию программа автоматизированной системы контроля НДС (далее АСК НДС). Ее применение позволяет сопоставлять информацию налоговой отчетности плательщиков НДС (электронная загрузка информации из книги покупок и книги продаж) и определять расхождения и правомерность действий контрагентов. В 2015 г. была введена АСК НДС-2, позволяющая налоговой службе взаимодействовать с хозяйствующими субъектами, обрабатывать первичную документацию и регистры бухгалтерского учета, проводить проверки контрольных цифр контрагентов, загружать данные по ИНН и выстраивать логически выверенную информацию о подозрительных трансакциях налоговых схем.

В 2016 г. АСК НДС-3 по своим функциональным возможностям стала более совершенной. При проверке плательщиков НДС обработке подлежат и данные отчетности, и информация, полученная с помощью контрольно-кассовой техники, которая сопоставляется с книгами продаж, покупок. Стоит отметить, что в категорию риска попадает любое предприятие вне зависимости 
от того, умышленно или случайно была произведена ошибка в налоговой документации, так как минимальное несоответствие становится поводом для проведения контрольных мероприятий.

С точки зрения дальнейшего совершенствования программного обеспечения АСК НДС планируется взаимодействие и объединение усилий ФНС с таможенной службой и с Центральным банком России, которые смогут смоделировать схему транзита денежных средств.

В настоящее время в России введена уголовная ответственность за формальное (номинальное) руководство фиктивной организацией, в том числе за предоставление необходимых для этого документов, в частности ст. 173.1 УК РФ («Незаконное образование (создание, реорганизация) юридического лица») и 173.2 УК РФ («Незаконное использование документов для образования (создания, реорганизации) юридического лица») [Теневая экономика.., 2015].

С 2016 г. произошло ужесточение мер ответственности за ранее ликвидированные организации: в течение трех лет после исключения из списка ЕГРЮЛ ФНС имеет право на осуществление проверочных мероприятий по «оконченной» финансово-хозяйственной деятельности в отношении учредителей хозяйствующего субъекта. При обнаружении сомнительных сделок, фиктивных посреднических связей и трансакционных операций на счете фирмы налоговая служба может предъявить претензии о необходимости погашения недоимок по бюджетным платежам, в том числе штрафные санкции (при наличии доказательной базы). Недобросовестные или неразумные действия, которые подвергали деятельность предприятий определенному риску, также могут выступать в качестве подтверждения обозначенных претензий ${ }^{3}$.

\section{Типы фиктивных компаний}

С учетом изощренности «серых» схем все фиктивные организации можно разделить на две группы [Гришин, 2012].

1. Противозаконные фирмы, которым присущ высокий уровень риска: в трансакциях и «обналичивании» участвуют

${ }^{3}$ Федеральный закон от 08.02.1998 № 14-Ф3 «Об обществах с ограниченной ответственностью» [Эл. pecypc]: URL: http://www.consultant.ru/document/cons_doc_ LAW_17819/ 
крупные денежные суммы; деятельность сопровождается оформлением подложных документов, позволяющих маскировать нарушения финансового законодательства и иные злоупотребления, которые можно определить в процессе налоговых проверок и следственных действий. Фактическое и номинальное руководство, как правило, осуществляют разные люди. Регистрация проводится по подложным или утерянным документам. Фактическое местонахождение определить невозможно. Срок жизни такой фирмы - от нескольких месяцев до 2-3 лет. Составление обязательной отчетности (как правило, с недостоверными или нулевыми показателями) может сопровождаться уплатой символической суммы налоговых платежей и взносов во внебюджетные фонды.

2. Реальные фирмы, осуществляющие сомнительные виды деятельности: они зарегистрированы по существующему юридическому адресу, периодически составляют необходимую отчетность, ведут бухгалтерские документы и оформляют официальный сайт. Систематическое ужесточение налоговой системы, административной и уголовной ответственности за неплатежи в бюджет провоцирует развитие таких фирм. Зная критерии ведения предпринимательской деятельности, на которые органы финансового контроля обращают повышенное внимание, учредители покупают действующие предприятия с законной историей сделок и используют их для запутывания следов при формировании расходов и неучтенных денежных средств, для уклонения от уплаты налогов и взносов, «дробления» сумм и придания законности расчетным операциям, а также «обналичивания» средств. При необходимости такие фирмы могут участвовать во встречных проверках и предоставлять сведения о контрагентах, что является своеобразной системой защиты при финансовом контроле. Их обычный срок существования на рынке - от двух до восьми лет.

\section{Как бороться}

С целью проверки факта существования фирмы-однодневки, как правило, используется следующий комплекс предварительных мероприятий:

- получение из органов ФНС России копии регистрационного дела проверяемой организации; 
- получение расчетного счета фирмы (с копиями юридического дела, с указанием IP-адресов Банка-клиента);

- получение сведений из органов Росфинмониторинга о совершении организацией подозрительных операций;

- установление личности директора, с последующем получением объяснения;

- получение сведений от провайдеров сети «Интернет» о фактическом лице (организации), пользующемся системой «Банк-клиент»;

- анализ движения средств по расчетному счету (как правило, у фирмы-однодневки не предусмотрены статьи расходов по оплате труда, коммунальных услуг, поступление и списание денежных средств происходят по различным основаниям, движение по счету носит транзитный характер и т.п.);

- проверка расчетных счетов «связанных» организаций с определением конечных получателей денежных средств (как правило, ими оказываются физические лица или ИП).

Для получения этих сведений используются информационные ресурсы ФНС, арбитражного суда, Федеральной службы государственной регистрации, кадастра и картографии, электронные площадки по реализации имущества должников, Единый федеральный реестр сведений о банкротстве, Информационная база «СПАРК», результаты проверок органов государственного финансового контроля, результаты встречных проверок с контрагентами, финансовая (бухгалтерская, налоговая) отчетность предприятия.

Сложность борьбы с «фирмами-однодневками» связана в первую очередь с латентностью их деятельности, в связи с чем главная задача, стоящая перед законодателем, состоит не просто в выявлении недобросовестных «контор», а в ведении превентивных мер в порядке создания и ведения предпринимательской деятельности. Необходимо вывести бизнес из теневого сектора экономики.

Рассматривая проблемы противодействия незаконной деятельности, отметим некоторые спорные моменты.

- Юридические лица могут попасть под категорию сомнительных из-за неотражения (даже без прямого умысла) ряда отчетных данных или хозяйственных операций, связанных с НДС. 
- Одним из обстоятельств, которое может инициировать «сверхплановую» налоговую проверку (в процессе которой придется предоставить всю необходимую документацию за предшествующие периоды), является неосторожность (неосмотрительность) в выборе поставщика или покупателя («однодневка» с деловыми оборотами).

- По итогам контроля возможны налоговые споры, которые требуют от предприятий дополнительных издержек.

- Отмечаются частые случаи отказа в регистрации юридического лица (особенно из-за невыплаченной ранее задолженности либо ликвидации по решению суда).

В связи с изложенным можно рекомендовать компаниям, участвующим в сделках по консолидации бизнеса, для минимизации рисков, возникающих при дополнительных проверках, не создание новой организации, а выделение филиалов на базе законно действующей: в этом случае предприятие имеет определенную репутацию, смена устава или руководителя не подвергается последующей проверке.

\section{Выводы и предложения}

По мнению авторов, государственный механизм противодействия развитию фирм-однодневок должен заключаться в наиболее широком охвате сфер предпринимательской деятельности. Кроме того, можно рекомендовать:

1. Введение мер ответственности за обналичивание денежных средств (одну из самых распространенных целей создания фиктивных организаций). В настоящее время в законодательных нормах отсутствует наказание за услуги конспиративных денежных переводов в наличную форму при посредничестве коммерческих организаций, в результате чего неучтенные денежные средства становятся товаром в предпринимательской сфере. Уголовно-правовой механизм нуждается в доработке с точки зрения привлечения к ответственности за конспиративные финансовые операции.

2. При использовании схем, связанных с незаконным получением субсидий (цель деятельности организации лишь формально совпадает с установленными требованиями), необходимо доработать контрольный механизм последующей проверки. Как показывает пример агропромышленного комплекса (в котором 
традиционно высок уровень господдержки), важен предварительный контроль получателей средств. Жесткий регламент условий получения бюджетных ассигнований должен стать своеобразным фильтром, а последующий контроль - обеспечить анализ отчетной документации, отражающей целевое расходование и фактический контроль реализованных средств. К сожалению, органы государственного финансового контроля зачастую пренебрегают этим. Схемы нецелевого использования субсидированной помощи широко распространены, что подтверждается судебной практикой. Как правило, в контрактах не прописываются ни ответственность получателя, ни контрольные мероприятия.

3. Отсутствие четкой методологии по выявлению подконтрольности фиктивных организаций требует разработки соответствующего механизма. Выявление контролирующих лиц не является основной целью налоговых органов в борьбе с фирмами-однодневками. Пока на практике применяется концепция ответственности за неосторожность действий при выборе контрагента. Иначе говоря, неосмотрительный покупатель попадает в категорию «причастных лиц», в связи с чем с него, как правило, взыскиваются причитающиеся суммы налога без дальнейшего поиска и уточнения конечного бенефициара фирмы - участницы сомнительной сделки. На наш взгляд, проверочные мероприятия должны концентрироваться не на партнерах фирмы, а на лице, получающем непосредственную выгоду, путем выстраивания цепочки действий подконтрольной организации.

4. В борьбе с контрабандой в качестве возможного решения проблемы можно предложить лицензирование участников внешнеэкономической деятельности. Также защитную функцию будет выполнять штрих-кодовое обозначение продукции с автоматическим категорированием соответствующих пошлин и цен в информационной базе (QR-код). Возможно использование $\mathrm{ACK}$ НДС в рамках деятельности Федеральной таможенной службы для оперативной регистрации и обмена данными по экспортноимпортным операциям с системой прохождения грузов (товаров).

5. В сфере государственных закупок следует ужесточить критерии отбора участников с помощью единой информационной базы, на основе системы «СПАРК». При необходимости предприятие - участник торгов должно быть готово обосновать 
низкий уровень цены (методология расчета и, при необходимости, гарантийное письмо).

Таким образом, в сегодняшней России теневая экономика все еще представляет угрозу для отечественного рынка и наносит значимый ущерб госбюджету. Действующие государственные меры противодействия теневому сектору недостаточно результативны и в большей степени направлены на ужесточение правил работы легальных субъектов хозяйственной системы. Разработка единого методологического подхода к определению масштабов теневой экономики позволит выявить ключевые факторы и инструменты такого противодействия и усилить его эффективность. В рамках стратегии экономической безопасности России целесообразно реализовать комплексный подход к формированию и реализации программы противодействия теневым процессам, основанной на межведомственном сотрудничестве и балансе интересов.

\section{Литература}

Артемьев Н.В., Латов Ю.В. Институционально-экономические причины "теневизации" малого бизнеса России // Terra Economicus. 2015. Т. 13. № 1. C. 61-72.

Барсукова С.Ю. Неформальная экономика. М.: Издательский дом ГУ ВШЭ, 2004. 448 c.

Буров В.Ю. Теневая экономика и малое предпринимательство: теоретические и методологические основы исследования / Монография. Чита: ЗабГУ, 2014. 204 c.

Буров В.Ю. Теоретические основы исследования теневой экономики: ретроспективный анализ // Теневая экономика. 2017. Т. 1. № 2. С. 57-72.

Глушков В.В. Теневые процессы в экономике: области формирования и динамика распространения // Вестник Волгоградского государственного университета. Серия 3: Экономика. Экология. 2008. № 2. С. 22-27.

Гришин А. В. Роль фирм - «однодневок» в экономике и налоговой системе России и способы борьбы с ними //Международная научно-практическая конференция «Проблемы противодействия уклонению от уплаты налогов на современном этапе развития российской налоговой системы» (20-21.09.2012 г;; Иркутск), Иркутск: Изд-во БГУЭП, 2012. 298 с. [С. 53-58].

Колесников В.В. Феномен криминализации в экономике: понятие, связь с реформами и правовым регулированием // Российский журнал правовых исследований. 2016. № 3 (8). С. 20-33. 
Колесников В.В. Экономическая теория права. Экономическая теория теневого сектора хозяйства, преступности и эффективности противодействия ей. Уч. пособие / Санкт-Петербург, 2015.

Латов Ю.В. Теневая экономика: учеб. пособие для вузов / Ю.В. Латов, С.Н. Ковалев; под ред.д.п.н., д.ю.н. проф. В.Я. Кикотя; д.э.н. проф. Г.М. Казиахмедова. М.: Норма, 2006. 336 с.

Олейник А. Н. Институциональная экономика / Уч. пособие. М.: ИНФРАM, 2002. $416 \mathrm{c}$.

Социология экономической преступности / Яковлев А.М.; Отв. ред.: В.Н. Кудрявцев М.: Наука, 1988. 256 с.

Теневая экономика и уголовный закон / Под ред. Д.Г. Макарова М.: Юрлитинфо, 2015. 216 с.

Dallago B. The «Second Economy»: A Mechanism for the Functioning of Society in Eastern Europe // Journal of the Washington Institute for Valuesitin Public Policy. Washington, D. C. Spring 1991. Vol. 1. № 1. P. 76-113.

Gutmann P. The Subterranean Economy // Financial Analysts Journal. 1977. № 34. P. 20.

Schneider F., Enste D. Shadow economies: Size, Causes and Consequences // Journal of Economic Literature. 2000. Vol. 38. № 1. P. 77-114.

Статья поступила 31.05.2018.

\section{Summary}

Mikhaylova N.S., The Ural legal institute of the Ministry of Internal Affairs of the Russian Federation, Yekaterinburg

Markov S. E., operative Management of economic security and anti-corruption Regional Office of the Ministry of Internal Affairs of Russia across the Sakhalin region, Yuzhno-Sakhalinsk

\section{Bogus Organizations: to Find and Neutralize}

In article the problem of distribution of the fictitious organizations which have arisen in development of the shadow phenomena in economy because of which the country annually rises incurs huge losses and there are shortages in the budget. The typical signs of short-lived firms, indicators indicating tax risks are listed. Also authors have presented the genesis of formation of the fictitious organizations and directory systems allowing to create methodical tools by determination of their quantity. To establish volumes and scales of shadow economy rather difficult as activity has latent character, thus, according to the experts and average values of techniques it is possible to define (with a high share of an error) only the approximate number of the fictitious organizations. On the basis of data of official statistics (the SPARK program allowing to define the index of due discretion) and by means of graphic display of a situation, authors have presented dynamics reflecting tendencies on reduction of number of the considered firms. Despite the specified fact, the problem remains unresolved-shadow processes continue the development. In article actions for reduction of number of the considered organizations are also offered.

Shadow economy; short-lived firm; business; indicators; counteraction 


\section{References}

Artemyev N.V., Latov Yu.V. (2015) Institutional and economic reasons of "tenevization" of small business of Russia. Terra Economicus. T. 13. No. 1. Pp. 61-72. (In Russ.)

Barsukova S.Yu. (2004) Neformalnaya ekonomika. Moscow: GU VShE Publ. 448 p. (In Russ.)

Burov V. Yu. (2014). Shadow economy and small business: theoretical and methodological bases research / Monograph. Chita. 204 p. (In Russ.)

Burov V. Yu. (2017) Theoretical bases of a research of shadow economy. Retrospective analysis In Shadow economy. T. 1. No. 2. Pp. 57-72. (In Russ.)

Glushkov V.V. (2008) Shadow processes in economy: fields of formation and dynamics of distribution In Bulletin of the Volgograd state university. Series 3: Economy. Ecology. No. 2. Pp. 22-27. (In Russ.)

Grishin A.V. (2012) A role of firms - "something ephemeral" in economy and the tax system of Russia and ways of fight against them In the International scientific and practical conference "Problems of Counteraction to Evasion of Taxes at the Present Stage of Development of the Russian Tax System", Irkutsk: BGUEP Publ. Pp. 53-58. (In Russ.)

Kolesnikov V.V. (2016) A criminalization phenomenon in economy: concept, connection with reforms and legal regulation In Russian magazine of legal researches. No. 3 (8). Pp. 20-33. (In Russ.)

Kolesnikov V.V. (2015). The economic theory is right. Economic theory of the shadow sector of economy, crime and efficiency of counteraction to her. Manual. St. Petersburg. 100 p. (In Russ.)

Latov Yu.V. (2006) Shadow economy: studies. a grant for higher education institutions. Yu. V. Latov, S. N. Kovalyov; under the editorship of dative of N, ю. N prof. V. Ya. Kikotya; Dr. Econ.Sci. prof. G. M. Kaziakhmedova. Moscow: Norm Publ. 336 p. (In Russ.)

Oleynik A. N. (2002). Institutional economy. Manual. Moscow: INFRA-M Publ. 416 p. (In Russ.)

Sociology of economic crime. Yakovlev A. M.; Edition: Kudryavtsev V.N. M.: Science, 1988. 256 p. (In Russ.)

Shadow economy and the criminal law (2015). Under the editorship of Makarov D. G. M.: Yurlitinfo. 216 p. (In Russ.)

Dallago B. (1991) The «Second Economy»: A Mechanism for the Functioning of Society in Eastern Europe. Journal of the Washington Institute for Valuesitin Public Policy. Washington, D. C. Spring. Vol. 1. No. 1. Pp. 76-113.

Gutmann P. (1977) The Subterranean Economy. Financial Analysts Journal. No. 34. P. 20

Schneider F., Enste D. (2000) Shadow economies: Size, Causes and Consequences. Journal of Economic Literature. Vol. 38. No.1. Pp. 77-114. 